Rev. Int. Contam. Ambie. 33 (3) 421-435, 2017

DOI: 10.20937/RICA.2017.33.03.06

\title{
EVALUACIÓN DE LA FITOTOXICIDAD DE ACEITE AUTOMOTRIZ USADO CON Vicia faba Y Phaseolus coccineus
}

\author{
Ezel Jacome GALINDO PÉREZ ${ }^{1,3 *}$, Roberto Rivelino OCAÑA SOTO², \\ Blanca Estela CHÁVEZ SANDOVAL ${ }^{2,4}$, Felix Antonio NARANJO CASTAÑEDA², \\ Martha MARTÍNEZ GARCÍA ${ }^{1}$, Jorge Eduardo CAMPOS CONTRERAS ${ }^{1}$ y Francisco GARCÍA FRANCO ${ }^{3}$
}

${ }^{1}$ Facultad de Estudios Superiores Iztacala, Universidad Nacional Autónoma de México. Avenida de los Barrios 1, Colonia Los Reyes Iztacala Tlalnepantla, Estado de México, México, C. P. 54090

${ }^{2}$ Universidad Autónoma Metropolitana, Unidad Azcapotzalco. Avenida San Pablo 180. Colonia Reynosa Tamaulipas, Delegación Azcapotzalco, Ciudad de México, México, C. P. 02200

${ }^{3}$ Universidad Autónoma Metropolitana, Unidad Xochimilco. Calzada del Hueso 1100, Colonia Villa Quietud, Delegación Coyoacán, Ciudad de México, México, C. P. 04960

${ }^{4}$ Departamento de Bioquímica, Escuela Nacional de Ciencias Biológicas, Instituto Politécnico Nacional. Prolongación de Carpio y Plan de Ayala, Colonia Santo Tomás, Delegación Miguel Hidalgo, Ciudad de México, México, C. P. 11340

*Autor para correspondencia: ez_gp553381@hotmail.com

(Recibido octubre 2015; aceptado octubre 2016)

Palabras clave: bioindicador, bioaumentación, bioestimulación, composta, lixiviados, aceite usado

\section{RESUMEN}

Actualmente existe una enorme generación de hidrocarburos residuales originados por la utilización de combustibles fósiles, que afectan negativamente a organismos y ecosistemas. De manera particular, los aceites lubricantes automotrices usados representan uno de los contaminantes más recalcitrantes por su larga permanencia y lento proceso de degradación. Esta situación hace urgente el desarrollo de trabajos que permitan evaluar la toxicidad de este tipo de residuos. En el presente trabajo se demostró la respuesta que tienen dos sistemas biológicos vegetales: Vicia faba y Phaseolus coccineus, durante su desarrollo, al crecer en suelo contaminado con aceite automotriz usado. Se realizó el monitoreo de los parámetros temperatura, $\mathrm{pH}$ y humedad del sustrato a lo largo del todo el proceso de crecimiento de ambas especies. Se observó un mayor porcentaje de germinación en las plántulas de $P$. coccineus $(78 \%$ ), las variables que determinan el monitoreo de toxicidad para estas especies (altura de la planta, grosor del tallo, longitud radicular, volumen radicular y concentración de clorofila) mostraron diferencias significativas entre los tratamientos de suelo con aceite usado y el suelo testigo $(\mathrm{p} \leq$ $0.05)$. El análisis de correlación mostró que las variables más relacionadas fueron altura y longitud radicular $\left(\mathrm{R}^{2}=0.74\right)$ y longitud radicular y volumen radicular $\left(\mathrm{R}^{2}=0.85\right)$. La especie que tuvo mayor tolerancia a las concentraciones de aceite fue $P$. coccineus, lo que nos permite verificar que aún con una biodegradación microbiana previa, el suelo tratado contienen trazas de hidrocarburos que puede inhibir el crecimiento de $V$. faba y $P$. coccineus.

Key words: bioindicator, bioaugmentation, biostimulation, compost, leachate, waste oil 


\begin{abstract}
There is a huge generation of residual hydrocarbons resulting from the use of fossil fuels, which adversely affect organisms and ecosystems. The automotive wasted lubricating oil represents one of the most recalcitrant pollutants because its long persistence and slow degradation. That is why it is very important to carry out studies to assess the toxicity of this residue. In this work the response of two plant species, Vicia faba and Phaseolus coccineus, was evaluated during its growth in contamined soil with automotive wasted oil. The monitoring of temperature, $\mathrm{pH}$ and humidity of substrate was done along the growth process in both species. A higher percentage of germination was observed in seedlings of $P$. coccineus $(78 \%)$. The variables that determine toxicity in plants (height, stem thickness, root length, root volume and concentration of chlorophyll) show significant differences between soil contamined with wasted oil and the control soil $(\mathrm{p} \leq 0.05)$. The correlation analysis showed that the most related variables were height-root length $\left(\mathrm{R}^{2}=0.74\right)$ and root length-root volume $\left(\mathrm{R}^{2}=0.85\right)$. The species that has greater tolerance to the hydrocarbon concentrations was $P$. coccineus. It was also possible to note that the prior treatment of composting in both soils is not sufficient to inhibit the toxicity of the wasted oil to grow $V$. faba and $P$. coccineus.
\end{abstract}

\section{INTRODUCCIÓN}

El manejo inadecuado de los materiales peligrosos, principalmente de los residuos derivados del petróleo tales como gasolinas, diésel y aceite automotriz quemado han generado, a escala mundial y local, un problema importante de contaminación de suelos, aire y agua. La contaminación de suelos provocada por el aceite automotriz se ha agravado, induciendo una daño significativo en diferentes partes del mundo, lo que se debe a un mal manejo en su disposición final, incorporándolo muchas veces al sistema de drenaje o directamente en el suelo, lixiviándose gradualmente, impactando en la calidad de las aguas receptoras (Mills et al. 2006).

En el suelo el aceite quemado impide el intercambio gaseoso con la atmosfera, induciendo diferentes cambios físicos y químicos y generando compuestos con una mayor toxicidad como benceno, naftaleno y fenantreno, entre otros (Meckenstock y Mouttaki 2011). Estos compuestos llegan a destruir la estructura terciaria de las proteínas, desnaturalizan enzimas y deshidratan células, provocando afecciones en las poblaciones microbianas del suelo (Miranda y Restrepo 2005, Benavides et al. 2006).

La dificultad para remover el aceite quemado en los diferentes sistemas ambientales, principalmente en la matriz del suelo, ha llevado a implementar nuevas tecnologías para su remoción. Una alternativa es la biodegradación microbiana, que constituye el principal proceso de biorremediación de suelos contaminados por compuestos derivados de hidrocarburos (Prince 1993). Uno de los objetivos de esta biotecnología es la transformación de los hidrocarburos por las bacterias, que al utilizarlo como fuente de carbono, permiten el rompimiento de los compuestos y cadenas de hidrocarburos, obteniendo como producto final dióxido de carbono y agua (Jong-Su et al. 2009, Lladó 2012).

Las principales ventajas de la degradación microbiana en comparación con otras tecnologías, tales como las fisicoquímicas, son los bajos costos durante el proceso de remoción y eliminación de contaminantes, así como una mayor seguridad, ya que no se emplean químicos que puedan dañar la salud humana y el ambiente (Lladó 2012).

Sin embargo, en ocasiones la biodegradación no siempre reduce en su totalidad las trazas de compuestos dañinos para otros organismos debido al tiempo de tratamiento y exposición de esta técnica, es por ello que se debe probar la toxicidad de los compuestos finales del proceso de remediación microbiana en otros sistemas biológicos (Castillo 2004).

Las plantas son uno de los sistemas biológicos más utilizados para bioensayos toxicológicos en suelo; muestran una diagnosis o predicción de los daños provocados por los diferentes contaminantes ambientales, siendo relativamente fáciles de estudiar las reacciones fisiológicas, bioquímicas, los mecanismos de adaptación y la mortalidad (Benavides et al. 2006).

La resistencia que presentan las plantas a los contaminantes viene determinada por diferentes factores, ya sean químicos, físicos y biológicos. Generalmente los factores químicos dependen de la composición química, dosis, y formulación; en cuanto a los factores biológicos, los determinan las 
estructuras anatómicas y morfológicas de los órganos y tejidos vegetales, así como las etapas de desarrollo en las que pueden estar expuestas (Pernía et al. 2008).

Entre los efectos fisiológicos más comunes que se presentan en las plantas ante un estresor químico se encuentra la inhibición de la germinación de las semillas, la reducción en la tasa de crecimiento, la reducción en la velocidad de asimilación de nutrientes, la perturbación en las funciones de los estomas durante el intercambio gaseoso y la evapotranspiración, la reducción de los pigmentos fotosintéticos (clorofila $\alpha, \beta$ y carotenoides) y la funcionalidad de las membranas celulares entre otras (García et al. 2012, Zarinkamar et al. 2013).

$V$. faba es una de las especies más utilizadas para evaluar el efecto de la toxicidad de diferentes sustancias químicas, debido a la sencillez para realizar pruebas citogenética y de efectos fisiológicos, utilizándose como bioindicador importante para evaluar múltiples contaminantes de suelos, sedimentos, materiales orgánicos, agua y efluentes industriales (Yu et al. 2013). Asimismo, esta especie se encuentra durante todo el año, es económica y fácil de cultivar (Mecozzi y Sturchio 2015).

$P$. coccineus es una especie con un amplio umbral de tolerancia, siendo utilizada para procesos de fitorremediación de diversos compuestos, principalmente hidrocarburos, reportándose una alta adaptación a suelos contaminados por combustóleo (Sangabriel et al. 2006, Ferrera-Cerrato et al. 2007).

Es por ello que el objetivo del presente trabajo fue determinar el efecto fitotóxico de los hidrocarburos residuales del aceite automotriz usado, el cual fue tratado previamente por degradación microbiana. Para ello, se evaluaron las variables agronómicas (altura de la planta, grosor del tallo, longitud radicular, volumen radicular y concentración de clorofila) de dos especies de plantas utilizadas como bioindicadores de efectos tóxicos (Vicia faba y Phaseolus coccineus).

\section{MATERIALES Y MÉTODOS}

Las semillas de ambas especies se obtuvieron en el mercado Sonora de la Ciudad de México. Las semillas fueron desinfectadas y escarificadas con una dosis de hipoclorito de sodio al $5 \%$, dejándose remojar durante un periodo de $15 \mathrm{~min}$, posteriormente fueron lavadas con agua destilada para su siembra en macetas con su respectivo sustrato (Rao et al. 2006, Ates 2011, Terefe et al. 2015).

El sustrato utilizado para el crecimiento de las plantas fue obtenido después de un proceso de composteo de residuos vegetales de jardín sometidos a tres distintos tipos de tratamientos con y sin presencia de aceite automotriz usado. Los tratamientos evaluados fueron: composta madura como testigo (CM), composta contaminada con aceite (CA) y composta bioaumentada contaminada con aceite (CBCA). La bioaumentación y bioestimulación de este último tratamiento se realizó incorporándole composta de residuos vegetales a una matriz de aceite automotriz y el hongo Aspergillus niger degradador de hidrocarburos aislado por Chávez y Castro (2013).

Las concentraciones de hidrocarburos iniciales fueron mayores de $50000 \mathrm{mg} / \mathrm{kg}$ lo que corresponde a concentraciones de fracciones pesadas de hidrocarburos, estas concentraciones fueron determinadas por García (2005), utilizando un cromatógrafo de gases, superando los límites máximos permisibles para fracciones de hidrocarburos en suelo (SEMARNAT 2003).

El diseño experimental consistió de un arreglo multifactorial de efectos fijos, con tres variables independientes por dos dependientes. Para cada tratamiento se utilizaron 3 semillas en una maceta conteniendo $2 \mathrm{~kg}$ de su respectivo sustrato, por triplicado. Por lo que fueron construidas un total de 18 unidades experimentales. Durante todo el proceso y hasta el momento del corte experimental, el suelo se mantuvo a humedad constante.

Se midió la temperatura ambiental con un termómetro de mercurio cercano al sitio donde se tenían las macetas, la humedad y el $\mathrm{pH}$ se registraron semanalmente con un termohigrómetro de suelo de dos sondas metálicas marca "Two way" (SEMARNAT 2002).

Se contabilizaron las semillas germinadas para cada tratamiento a los cinco días de experimentación y se evaluó su capacidad germinativa utilizando el índice de porcentaje de la germinación relativa de semillas (\% GRS) de acuerdo con lo reportado por Hoekstra et al. (2002), utilizando la siguiente fórmula modificada:

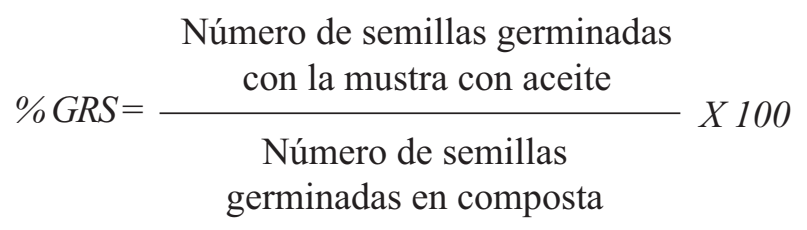

El primer corte del experimento se obtuvo a los 28 días, en el cual se eliminaron las plántulas más chicas de cada maceta, para solamente dejar una planta por maceta; el experimento concluyo a los 60 días. Para ambos cortes se elaboraron mediciones agronómicas, tales como altura de la planta, grosor del tallo, longitud radicular y volumen radicular. La altura de la planta se midió utilizando un flexómetro de $10 \mathrm{~m}$ y el grosor del tallo se midió utilizando un Vernier 
milimétrico. Se cortó la parte aérea al ras del suelo, se extrajo la raíz, que se lavó con agua destilada para medir su longitud y volumen radical de acuerdo con el volumen de agua desplazado en una probeta de 500 mL (Wu et al. 2005, García et al. 2012).

Se determinó la concentración de clorofila $\alpha$ y $\beta$, seleccionando las hojas que no presentaban daño aparente, se pesó un gramo de hojas frescas y se maceraron con un mortero de porcelana incorporándole $20 \mathrm{~mL}$ de acetona concentrada al $90 \%$. El homogeneizado se obtuvo en un cuarto oscuro para evitar la degradación de la clorofila (García et al. 2012) y se recuperó en tubos Ependorf, los cuales se protegieron con papel aluminio, y posteriormente se centrifugaron en una microcentrifuga refrigerada a $3000 \mathrm{rpm} \mathrm{y} 4{ }^{\circ} \mathrm{C}$. La cuantificación de los contenidos de clorofila $\alpha$ y $\beta$ se hizo en un espectrofotómetro de UV-VIS PerkinElmer lambda 35 a una longitud de onda de 663 y $645 \mathrm{~nm}$ (Arnol 1949). El contenido se expresó en $\mathrm{mg}$ de clorofila/g de material vegetal utilizando la siguiente formula (Shanee 2011):

Clorofila total $(\mathrm{mg} / \mathrm{g})=[(8.02 \times \mathrm{A} 663)+(20.20 \times$ $\mathrm{A} 645)] \times \mathrm{V} / 1000 \times \mathrm{W}$

Donde $\mathrm{V}=$ volumen del extracto $(\mathrm{mL})$

$\mathrm{W}=$ peso de hojas frescas $(\mathrm{g})$

Finalmente se realizó una comparación de los tratamientos con un análisis de varianza multivariado y la prueba de comparación de medias post-hoc de Tukey a un nivel de significancia de $\alpha=0.05$, para determinar si existieron diferencias significativas entre pares de medias de cada tratamiento. Se compararon las variables agronómicas (altura de la planta, grosor del tallo, longitud radicular, volumen radicular y concentración de clorofila) mediante el coeficiente de correlación de Pearson (Gutiérrez-Miceli et al. 2006, Ramírez et al. 2012).

\section{RESULTADOS Y DISCUSIÓN}

La temperatura ambiental promedio registrada durante los 60 días del experimento fue de $27^{\circ} \mathrm{C}$, la temperatura más baja se registró el día 28 llegando a $22.4^{\circ} \mathrm{C}$ y la temperatura máxima alcanzó $\operatorname{los} 34^{\circ} \mathrm{C}$ el día 24 (Fig. 1). Durante el experimento las temperaturas registradas fueron óptimas para el crecimiento de ambas especies. Se ha reportado que el rango de tolerancia para $V$. faba se encuentran entre los $2^{\circ} \mathrm{C}$ y los $30.9^{\circ} \mathrm{C}$, y su rango óptimo de crecimiento está entre los 12 y los $18^{\circ} \mathrm{C}$ (Prieto et al. 2007, Confalone et al. 2010,
García et al. 2012, List 2014). Para P. coccineus el rango es de los $2{ }^{\circ} \mathrm{C}$ a los $31{ }^{\circ} \mathrm{C}$, y el crecimiento óptimo ocurre en el rango de temperaturas de 16 a $18{ }^{\circ} \mathrm{C}$ (Gonzáles et al. 2001, Manzur 2013, Meza 2014).

En el caso del pH se obtuvo un registro promedio de 7.6 para los tres tratamientos. Los valores oscilaron en el rango alcalino de 8.0 y neutro de 7.0 (Fig. 1). Los resultados de $\mathrm{pH}$ obtenidos fueron apropiados para el desarrollo de las dos especies cultivadas, ya que $V$. faba es capaz de crecer en diferentes tipos de suelos con un $\mathrm{pH}$ que va desde de 5.5 a 9.0 (Bergareche et al.1988, Acuña 2011, List 2014). Respecto a $P$. coccineus las condiciones de $\mathrm{pH}$ para su óptimo desarrollo se encuentran entre 6.5 y 7.5 (Meza 2014). Existen reportes en los que se determina que el $\mathrm{pH}$ es un factor que puede afectar la disponibilidad de nutrientes y su absorción por las raíces de las plantas Sorghum bicolor y Linum usitatissumum en presencia de hidrocarburos. En dichos reportes se registraron valores ligeramente ácidos $(\mathrm{pH}=7.7)$ con fertilizantes de humus, mejorando la absorción de nutrientes en las plantas (Shirdam et al. 2008). Por lo tanto las condiciones de $\mathrm{pH}$ en los tratamientos de $V$. faba y $P$. coccineus permitieron un efectivo transporte de nutrientes hacia las plantas de ambas especies.

Durante los 60 días del experimento se obtuvo un porcentaje de humedad promedio del $69 \%$, este registro nos indica que la humedad en los tres tratamientos es adecuada para el crecimiento de $V$. faba, ya que se considera que las mejores condiciones de cultivo para esta especie se encuentran entre valores de 60 y 75 $\%$ (Agurto 2012), mientras que para $P$. coccineus la mejor condición es al 50 \% de humedad (Pinales 1995, Ferrera-Cerrato et al. 2007), debido a que las leguminosas mejoran la retención de humedad en suelos, gracias a la gran cantidad de nódulos en sus raíces (Escalante 2000, Villarreal-Romero et al. 2006, Acuña 2011).

El análisis de germinación demostró que los tratamientos que tuvieron menor \% GRS (62.5\%) fueron CA y CBCA para $V$. faba y CA para $P$. coccineus (Cuadro I). Esto se debe a que la presencia de aceite automotriz inhibe la germinación en estas especies, ya que en ocasiones las fracciones ligeras de los hidrocarburos son capaces de moverse a través de las membranas celulares (VanOverbeek y Blondeau 1954), de tal forma que en contacto con la semilla penetran en la cubierta, matando rápidamente al embrión, provocando una toxicidad aguda, por lo que hay retardo y reducción del porcentaje de germinación efectiva (Escalante 2000). El efecto inhibidor se podría atribuir también a características físicas y químicas del aceite, el cual tiene propiedades hidrofóbicas por lo que se llega a generar una película 

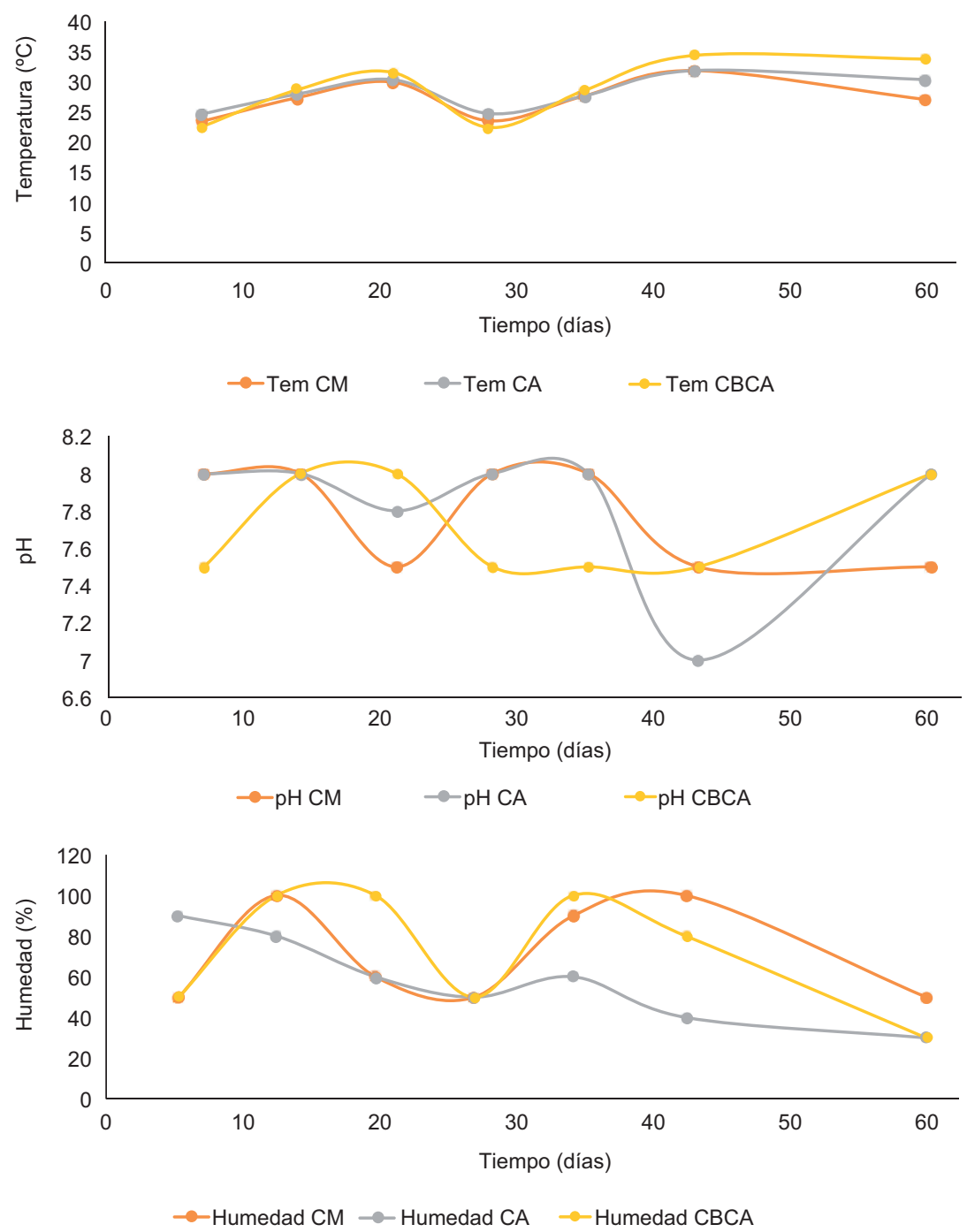

Fig. 1. Monitoreo de parámetros físicos y químicos (temperatura, $\mathrm{pH}$ y humedad) presente durante el ensayo fitotóxico. $\mathrm{CM}=$ composta madura, $\mathrm{CA}=$ composta con aceite, $\mathrm{CBCA}=$ composta con aceite bioaumentada

CUADRO I. PORCENTAJE DE LA GERMINACIÓN RELATIVA DE SEMILLAS (\% GRS) OBTENIDO PARA LOS TRES TRATAMIENTOS CON Vicia faba y Phaseolus coccineus

\begin{tabular}{lll}
\hline Especie & Tratamiento & $\%$ GRS \\
\hline V. faba & CM & 100 \\
V. faba & CA & 62.5 \\
V. faba & CBCA & 62.5 \\
$P$. coccineus & CM & 100 \\
$P$. coccineus & CA & 62.5 \\
$P$. coccineus & CBCA & 78 \\
\hline
\end{tabular}

$\mathrm{CM}=$ composta madura, $\mathrm{CA}=$ composta con aceite, $\mathrm{CBCA}=$ composta con aceite bioaumentada alrededor de las semillas, actuando como una barrera física tanto para la humectación de la testa como para el intercambio de oxígeno entre el suelo y la semilla, provocando una fase de latencia prolongada antes de su germinación (Adam y Duncan 2002).

Lo anterior demuestra que los sustratos utilizados para la germinación de las semillas de $V$. faba y $P$. coccineus en los tratamientos con presencia de aceite automotriz, contienen suficiente concentración del mismo como para inhibir su crecimiento, siendo los tratamientos CA para las dos especies evaluadas los más efectivos. Esto concuerda con los resultados obtenidos en diversas investigaciones (Khan y Shaukat 2009, Oyedeji et al. 2012, Ndubuisi et al. 2013, Zarinkamar et al. 2013) que evaluaron la fitotoxicidad 

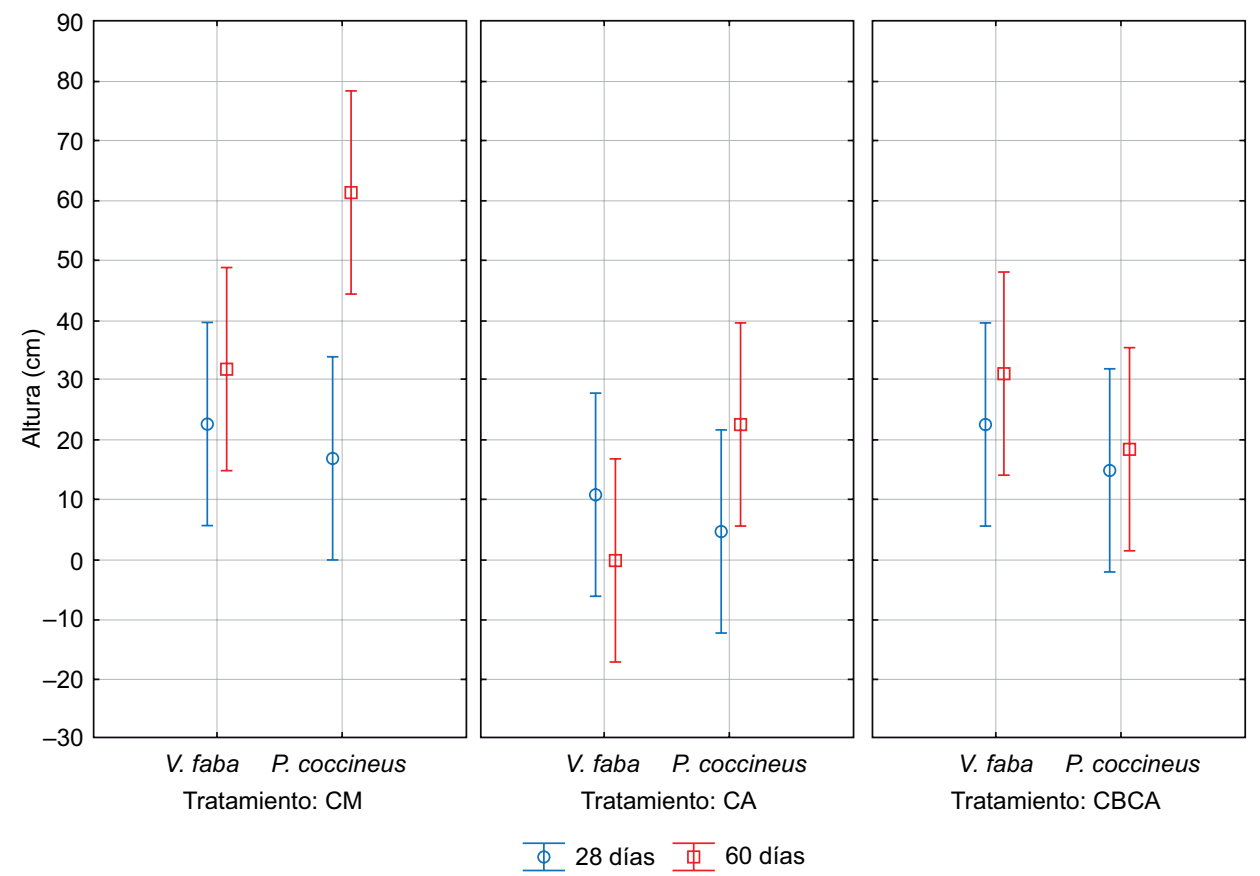

Fig. 2. Altura registrada de Vicia faba y Phaseolus coccineus a los 28 y 60 días de experimentación en tres diferentes tratamientos, donde $\mathrm{CM}=$ composta madura, $\mathrm{CA}=$ composta con aceite, $\mathrm{CBCA}=$ composta con aceite bioaumentada

de petróleo crudo en varias especies de plantas, concluyendo que la presencia de hidrocarburos limita, retarda e inhibe el porcentaje de germinación, atribuyéndoselo a las características del hidrocarburo y a las concentraciones presentes en el suelo.

Para los tratamientos testigo (CM) el \% GRS fue del $100 \%$ para las dos especies de plantas, seguida del tratamiento CBCA para la especie de $P$. coccineus $(78 \%)$. El alto porcentaje de germinación en este último tratamiento, está dado por la gran tolerancia que tiene $P$. coccineus a la presencia de hidrocarburos (Sangabriel et al. 2006). La testa de la semilla de esta especie llega a presentar cualidades que impiden la entrada del aceite, evitando el daño del embrión en comparación a las semillas de $V$. faba (Zarinkamar et al. 2013).

En cuanto a la variable de altura de cada tratamiento (Fig. 2) se observaron diferencias significativas entre el tratamiento testigo $(\mathrm{CM})$ de $P$. coccineus a los 60 días de desarrollo y los otros tratamientos (CA y CBCA). Las plantas de CM alcanzaron una altura de hasta $84 \mathrm{~cm}$, las plantas del resto de los tratamientos alcanzaron alturas por debajo de los 40 $\mathrm{cm}$. Para el caso de $V$. faba las condiciones se mantuvieron similares en todos los tratamientos. El mayor desarrollo también se presentó en el tratamiento testigo CM, llegando a alturas de hasta $67 \mathrm{~cm}$ a $\operatorname{los} 60$ días, y en el tratamiento CBCA se observó una altura máxima de $33 \mathrm{~cm}$. y para el caso del tratamiento CA no hubo supervivencia de las plántulas a los 60 días de exposición, por lo que en este último tratamiento existió una alta toxicidad provocada por los residuos de aceite.

La prueba diferencial de Tukey mostró diferencias significativas en el tratamiento de CM de $P$. coccineus a los 60 días con respecto a los tratamientos de $V$. faba y P. coccineus a los 28 y 60 días del corte experimental (Cuadro II).

CUADRO II. PRUEBA DE TUKEY PARA LA VARIABLE ALTURA ENTRE Vicia faba Y Phaseolus coccineus

\begin{tabular}{|c|c|c|c|}
\hline \multirow[t]{2}{*}{ Corte } & \multirow[t]{2}{*}{ Especie } & \multirow[t]{2}{*}{ Tratamiento } & $\begin{array}{c}\text { Tratamiento: CM } \\
\text { P. coccineus ( } 60 \text { días) }\end{array}$ \\
\hline & & & $\mathrm{p} \leq 0.05$ \\
\hline 28 días & $V . f a b a$ & $\mathrm{CA}$ & $0.010 *$ \\
\hline 28 días & P. coccineus & $\mathrm{CM}$ & $0.033 *$ \\
\hline 28 días & P. coccineus & $\mathrm{CA}$ & $0.003 *$ \\
\hline 28 días & P. coccineus & CBCA & $0.022 *$ \\
\hline 60 días & V. faba & $\mathrm{CA}$ & $0.001 *$ \\
\hline 60 días & P. coccineus & CBCA & $0.043 *$ \\
\hline
\end{tabular}

* = muestran los tratamientos que tuvieron diferencias estadísticas entre los diferentes tratamientos $(\mathrm{p} \leq 0.05)$, donde $\mathrm{CM}=$ composta madura, $\mathrm{CA}=$ composta con aceite, $\mathrm{CBCA}=$ composta con aceite bioaumentada 

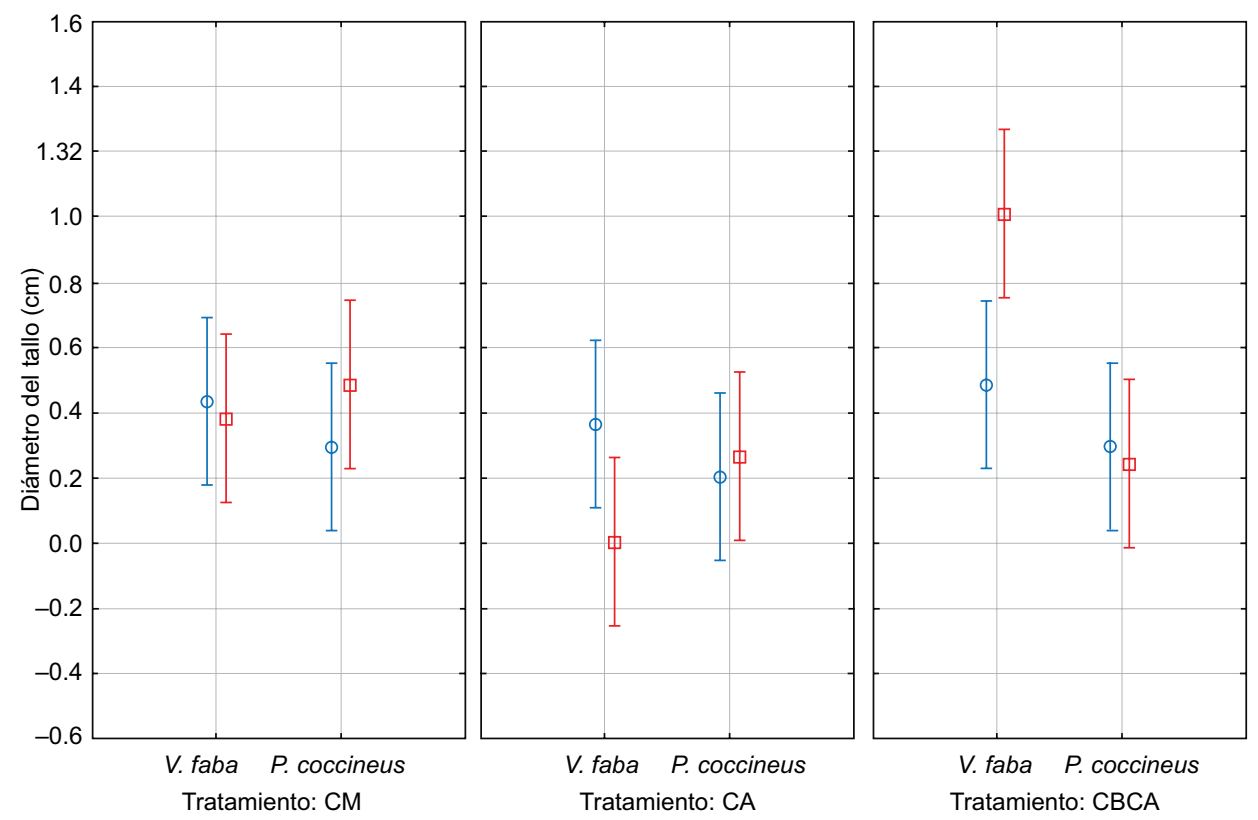

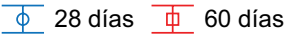

Fig. 3. Diámetro registrado para $V$. faba y $P$. coccineus a los 28 y 60 días de experimentación en tres diferentes tratamientos, donde $\mathrm{CM}=$ composta madura, $\mathrm{CA}=$ composta con aceite, $\mathrm{CBCA}=$ composta con aceite bioaumentad

El desarrollo óptimo en el tratamiento de CM para ambas especies vegetales se debe a que en la composta madura se tiene nutrientes, materia orgánica estabilizada, con gran cantidad de poblaciones microbianas benéficas para el desarrollo de la planta, ácidos húmicos y fúlvicos y bioactivadores de la fisiología (García-Albarado et al. 2010).

La presencia de hidrocarburos tiene una gran influencia en la interacción del suelo y las raíces de las plantas, afectando la química del mismo, evitando la liberación de nutrientes y la absorción de los mismos por la planta (Nwoko et al. 2007), provocando una disminución en el crecimiento de $V$. faba y $P$. coccineus. Esto concuerda con los experimentos realizados por Adenipekun et al. (2009) en donde observaron la reducción de la altura de Abelmoschus esculentus a concentraciones de $3.0 \% \mathrm{v} / \mathrm{p}$ de aceite automotriz quemado, teniendo su máximo crecimiento durante la tercera semana y posteriormente no mostro supervivencia a la sexta semana. Sin embargo, a bajas concentraciones de aceite se mantuvo un crecimiento óptimo para esta especie. Adenipekun et al. (2008), mencionan que la reducción de la longitud de las plántulas Corchorus olitorius es provocada por el contenido de humedad a las seis semanas, lo cual es generado por la estructura hidrófoba del aceite automotriz, disminuyendo con esto la disponibilidad de agua en suelo, concluyendo que la relación plantaagua del suelo podría haber sido afectada.

En el caso del diámetro del tallo, se registraron varianzas poco significativas, sin embargo, $V$. faba en el tratamiento de CBCA mostró una diferencia en el grosor de las plántulas a los 60 días, llegando a una longitud del diámetro del tallo de hasta $1.6 \mathrm{~cm}$ (Fig.3).

La prueba diferencial de Tukey, mostró diferencias significativas entre los tratamientos con presencia de hidrocarburos, principalmente en el tratamiento CBCA para V. faba a los 60 días de experimentación con respecto a los demás tratamientos (Cuadro III). Para los tratamientos CA y CBACA de $P$. coccineus a los 60 días, mostraron significancia con respecto al tratamiento CBCA de V. faba.

Por lo que el tratamiento con CBCA de $V$. faba tuvo el mayor grosor en el tallo de todas las unidades experimentales, observándose una estrecha relación entre la variable de altura y el diámetro del tallo, indicando que a mayor altura de la planta se debe de tener una buena estructura de sostén para la parte aérea de la misma y soportar la biomasa de hojas que se pueda generar (García-Albarado et al. 2010). Para el caso de los tratamientos con un déficit de longitud del tallo, este es provocado por la aireación insuficiente generada por el aceite automotriz, teniendo como consecuencia la pudrición del tallo y una reducción 
CUADRO III. PRUEBA DE TUKEY PARA LA VARIABLE DIÁMETRO DEL TALLO ENTRE Vicia faba Y Phaseolus coccineus

\begin{tabular}{|c|c|c|c|c|c|}
\hline \multirow{3}{*}{ Corte } & \multirow{3}{*}{ Especie } & \multirow{3}{*}{ Tratamiento } & \multicolumn{3}{|c|}{ Tratamiento } \\
\hline & & & $\begin{array}{c}\text { CBCA } \\
\text { V. faba (60 días) }\end{array}$ & $\begin{array}{c}\text { CA } \\
\text { P. coccineus (60 días) }\end{array}$ & $\begin{array}{c}\text { CBCA } \\
\text { P. coccineus (60 días) }\end{array}$ \\
\hline & & & \multicolumn{3}{|c|}{$\mathrm{p} \leq 0.05$} \\
\hline 28 días & $V . f a b a$ & $\mathrm{CA}$ & $0.0498 *$ & 0.9999 & 0.9998 \\
\hline 28 días & P. coccineus & $\mathrm{CM}$ & $0.0217^{*}$ & 0.9999 & 0.9999 \\
\hline 28 días & P. coccineus & $\mathrm{CA}$ & $0.0059 *$ & 0.9999 & 0.9999 \\
\hline 28 días & P. coccineus & CBCA & $0.0217^{*}$ & 0.9999 & 0.9999 \\
\hline 60 días & V.faba & CA & $0.0004^{*}$ & 0.9362 & 0.9620 \\
\hline 60 días & V. faba & CBCA & 1 & $0.0129 *$ & $0.0099 *$ \\
\hline
\end{tabular}

$*=$ muestran los tratamientos que tuvieron diferencias significativas $(\mathrm{p} \leq 0.05)$, donde $\mathrm{CM}=$ composta madura, $\mathrm{CA}=$ composta con aceite, $\mathrm{CBCA}=$ composta con aceite bioaumentada

en el crecimiento de la planta (Adenipekun 2008), ya que este sistema es el principal medio por el cual las planta transportan los nutrientes y el agua a la parte aérea (Azcón-Bieto y Talón 2008).

La variable longitud radicular presentó diferencias significativas en el tratamiento CM de $P$. coccineus a los 60 días, llegando a una longitud de hasta $64 \mathrm{~cm}$. En los tratamientos testigo (CM) de $V . f a b a$ a los 60 días se registraron longitudes de hasta $22.3 \mathrm{~cm}$. El tratamiento CBCA de $V$. faba a los 60 días alcanzó una longitud de $35 \mathrm{~cm}$ de largo y el de $P$. coccineus llegó a tener una longitud de $34 \mathrm{~cm}$ (Fig. 4).

Para la prueba Tukey de la variable longitud radicular, se presentaron diferencia en el tratamiento CM de la especie $P$. coccineus a los 60 días en comparación al tratamiento CA de $V$. faba (Cuadro IV), así como también entre $V$. faba CBCA y CA a los 60 días.
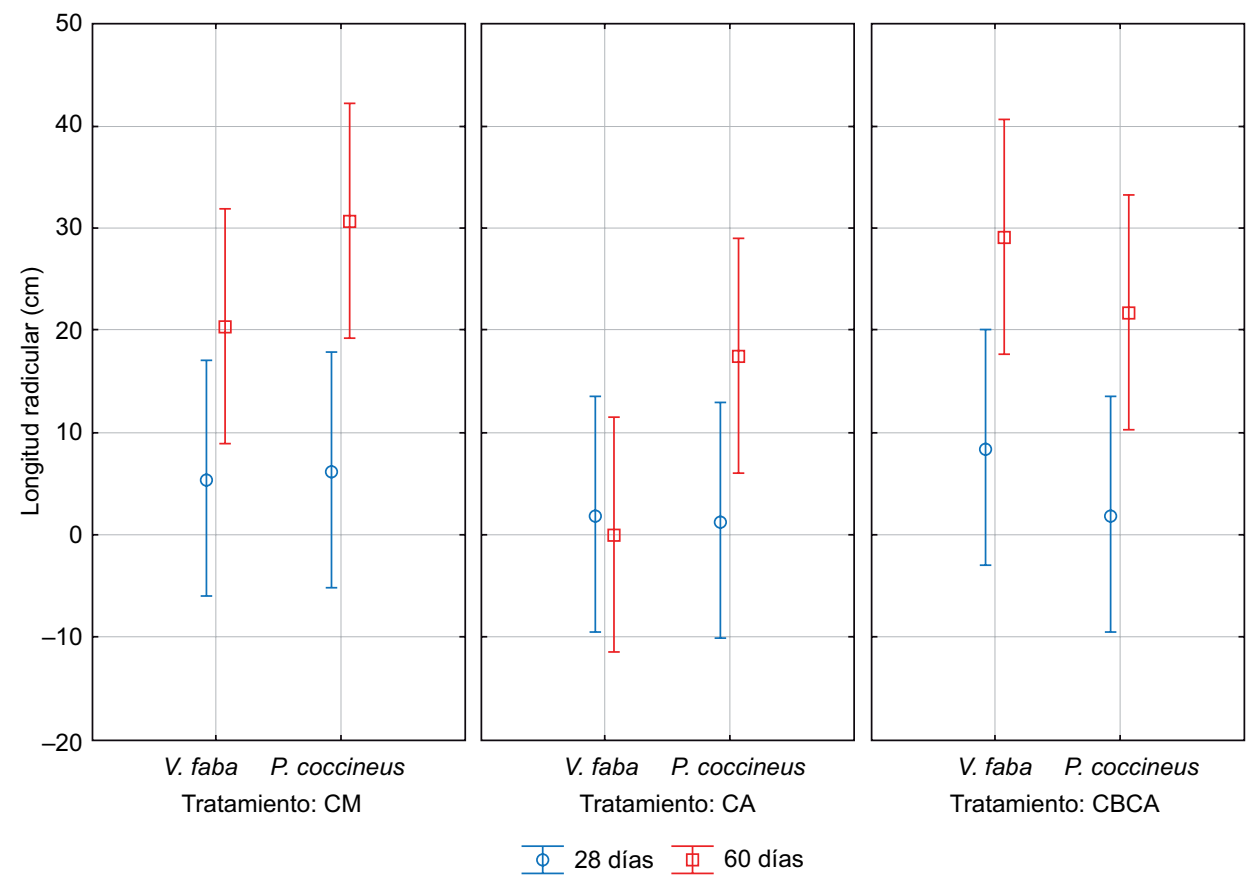

Fig. 4. Longitud radicular registrada en $V$. faba y $P$. coccineus a los 28 y 60 días de experimentación en tres diferentes tratamientos, donde $\mathrm{CM}=$ composta madura, $\mathrm{CA}=$ composta con aceite, $\mathrm{CBCA}=$ composta con aceite bioaumentada 
CUADRO IV. PRUEBA DE TUKEY PARA LA VARIABLE LONGITUD RADICULAR ENTRE Vicia faba Y Phaseolus coccineus

\begin{tabular}{llllc}
\hline & & \multicolumn{2}{c}{ Tratamiento } \\
\cline { 4 - 5 } Corte & Especie & Tratamiento & $\begin{array}{c}\text { CBCA } \\
\text { V.faba (60 días) }\end{array}$ & $\begin{array}{c}\text { CM } \\
\end{array}$ \\
\cline { 3 - 5 } & & & \multicolumn{2}{c}{$\mathrm{p} \leq 0.05$} \\
\hline 28 días & V.faba & CA & 0.066 & $0.041^{*}$ \\
28 días & $P$. coccineus & CM & 0.201 & 0.134 \\
28 días & $P$. coccineus & CA & 0.056 & $0.035^{*}$ \\
28 días & $P$. coccineus & CBCA & 0.067 & $0.042^{*}$ \\
60 días & V.faba & CA & $0.040^{*}$ & $0.024^{*}$ \\
\hline
\end{tabular}

$*$ = muestran los tratamientos que tuvieron diferencias significativas $(\mathrm{p} \leq 0.05)$, donde $\mathrm{CM}=$ composta madura, $\mathrm{CA}=$ composta con aceite, $\mathrm{CBCA}=$ composta con aceite bioaumentada

La variable de volumen radicular no mostró diferencias significativas entre tratamientos para ambas pruebas. El menor volumen radicular se presentó en el tratamiento CA P. coccineus, llegando a un promedio de $4.3 \mathrm{~cm}^{3}$. Para los tratamientos a los 60 días de CM y CBCA de ambas especies se mantuvo en un promedio de 10 y $11 \mathrm{~cm}^{3}$ de volumen radicular (Fig. 5).

Estos resultados indican que para ambas especies, al ser cultivadas con aceite automotriz (tratamiento CA) se ve afectado su crecimiento radicular. El crecimiento de la raíz, tanto en longitud como en volumen es perjudicado muchas veces por las condiciones físicas y químicas presentes en el sustrato en donde se desarrolle, teniendo modificaciones y afecciones determinadas por la falta de oxigenación del suelo, inducido por la presencia del hidrocarburo (Córdoba-Rodríguez et al. 2011).

La inhibición del crecimiento en $V$. faba para los tratamientos con aceite automotriz (CA y CBCA), se debe a la ineficiencia del sistema radicular de la planta para sustraer el agua del suelo. Las características físicas y químicas del aceite, causan un elevado estrés anóxico e hídrico en el sistema de raíz (Gogosz et al. 2010), provocando una ineficiente asimilación de

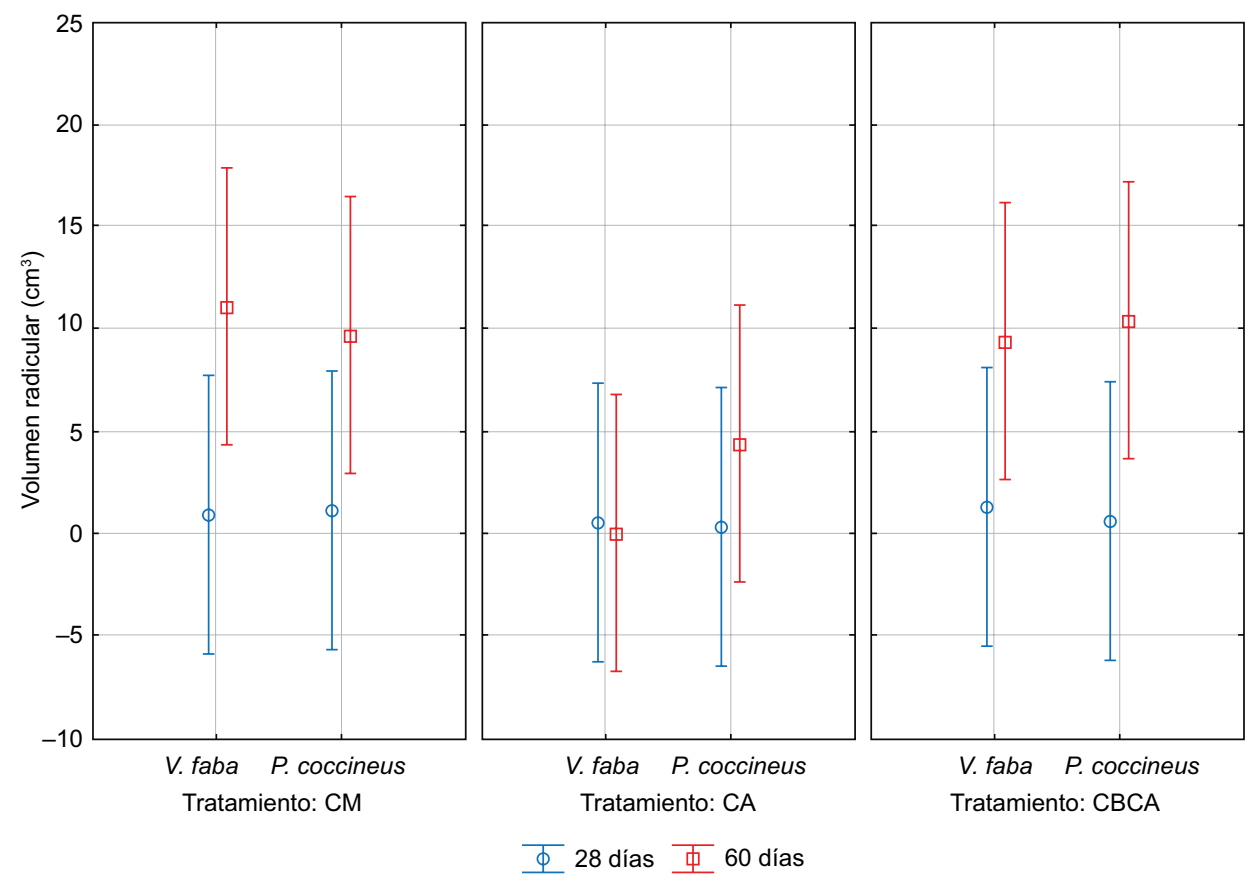

Fig. 5. Volumen radicular de $V$. faba y $P$. coccineus a los 28 y 60 días de experimentación en tres diferentes tratamientos, donde $\mathrm{CM}=$ composta madura, $\mathrm{CA}=$ composta con aceite, $\mathrm{CBCA}$ = composta con aceite bioaumentada 
nutrientes y productividad de la planta (Adenipekun y Oyetunji 2008, Rivera-Cruz et al. 2012). ReynosoCuevas et al. (2008) observaron daños en las raíces y una disminución en la longitud radicular en diferentes especies a medida que aumentaba la concentración de hidrocarburos.

El desarrollo de $P$. coccineus en los tratamientos con aceite se debe al sistema radicular que presenta esta leguminosa, la cual tiene una alta tolerancia a las concentraciones de aceite presentes en el sustrato. Existe una estrecha relación simbiótica entre los microorganismos de la composta bioaumentada y los que se encuentran en la parte de la rizósfera. Esta relación permite neutralizar compuestos altamente tóxicos y transportarlos a la parte aérea de la planta, ya sea como nutrientes o bioacumulándolos en la biomasa, a partir de enzimas que permiten mineralizar el aceite y otros hidrocarburos (Nwoko et al. 2007).

Algunas leguminosas como $P$. vulgaris, son capaces de remediar suelos contaminados con aceite, debido a su capacidad de fijar nitrógeno, manteniendo un equilibrio entre la relación C: $\mathrm{N}$ en el suelo. Aunque pueden presentar una reducción de nódulos en las cuando son sometidas a suelos con hidrocarburos (Nwoko et al. 2007).

Asimismo, $P$. coccineus llega a presentar una estructura radicular muy compleja, los nódulos fijadores de nitrógeno y los rizomas se pueden extender ampliamente, proporcionándole a la planta una extensa área de superficie en la raíz para el crecimiento de microorganismos, de tal manera que la planta llega a ser más tolerante al estrés (Cruz et al. 2012). Pueden existir otros factores que influyen en la eficiencia de simbiosis entre las raíces y los microorganismos del suelo, tal es el caso de la temperatura, humedad, $\mathrm{pH}$, materia orgánica, el potencial redox, la salinidad, la intensidad de la luz y el nivel de oxígeno (Merkl et al. 2005, Pernía et al. 2008).

La supervivencia de plantas cultivadas en suelos con petróleo se atribuye a la presencia de microorganismos que se encuentran en la zona de raíz o rizósfera, principalmente a las micorrizas que se asocian con ellas. Se ha reportado que a mayor concentración de microorganismos asociados a la rizósfera, se fomenta la degradación de hidrocarburos presentes en el suelo (Nwoko et al. 2007).

El crecimiento de $P$. coccineus en el tratamiento CBCA está relacionado con la bioaumentación previa de microrganismos degradadores de hidrocarburos. Lo anterior porque la relación $\mathrm{C}: \mathrm{N}$ se optimiza al permitir que los microorganismos transformen las moléculas complejas de los hidrocarburos en moléculas disponibles para las plantas (Merkl et al.
2005). Asimismo, el desarrollo de microorganismos nitrificantes en los suelos con hidrocarburos, permite equilibrar la relación $\mathrm{C}: \mathrm{N}$, enriqueciendo el suelo con nitrógeno, promoviendo un mayor desarrollo de las plantas de $P$. coccineus en tratamientos con presencia de aceite automotriz (Pino et al. 2012).

Pino et al. (2012), compararon dos técnicas biotecnológicas (bioaumentación y bioestimulación) para la recuperación de suelos contaminados con diésel, obteniendo una reducción del $93 \%$ de este compuesto. También Ogbonna (2007) estudió el efecto de la bioaumentación de aceite en suelo sobre el crecimiento de Abelmoschus esculentus, encontrando que al añadir microorganismos y fertilizantes, las plantas mostraban un mejor crecimiento y degradación de hidrocarburos, en comparación con las que no se encontraban sometidas a una bioaumentación.

El crecimiento de $P$. coccineus en el tratamiento CA se debe a la presencia de un mayor contenido de nutrientes en la composta utilizada, así como una alta cantidad de microorganismos. Estos microorganismos al desarrollarse en el proceso de composteo convencional, no presentan una adaptación especifica para la degradación de hidrocarburos, generando un menor desarrollo en el volumen y longitud radicular (Garrido-Hoyos et al. 2005).

Para los niveles de clorofila en los diferentes tratamientos se observaron diferencias significativas en el contenido de los pigmentos fotosintéticos (Fig. 6). La mayor diferencia se presentó entre el tratamiento CM y CBCA de $P$. coccineus, con una disminución en el tratamiento CBCA, así como en el tratamiento CA, llegando a concentraciones de hasta $1 \mathrm{mg} / \mathrm{g}$. Para el caso de $V$. faba no existieron diferencias significativas entre los tratamientos, registrando concentraciones promedio de clorofila de $1.7 \mathrm{mg} / \mathrm{g}$.

Para la prueba Tukey (DSH) de la variable concentración de clorofila, se obtuvieron diferencias significativas entre los tratamientos, sin embargo, las diferencias presentadas se deben a la supervivencia entre el tratamiento CA de $V$. faba (Cuadro V)

En el tratamiento CA y CBCA se obtuvo una disminución en la pigmentación en el caso de $P$. coccineus, implicando que los niveles del contenido de clorofila y pigmentos celulares están determinados por la concentración de hidrocarburos en el suelo. Las altas concentraciones de aceite automotriz disminuyen significativamente las formas disponibles de fósforo y potasio, siendo esenciales para un crecimiento y desarrollo óptimo, por lo tanto la reducción en su biodisponibilidad dará lugar a una reducción en el contenido de clorofila y otras biomoléculas esenciales (Akujobi et al. 2011, Wang et al. 2011). 

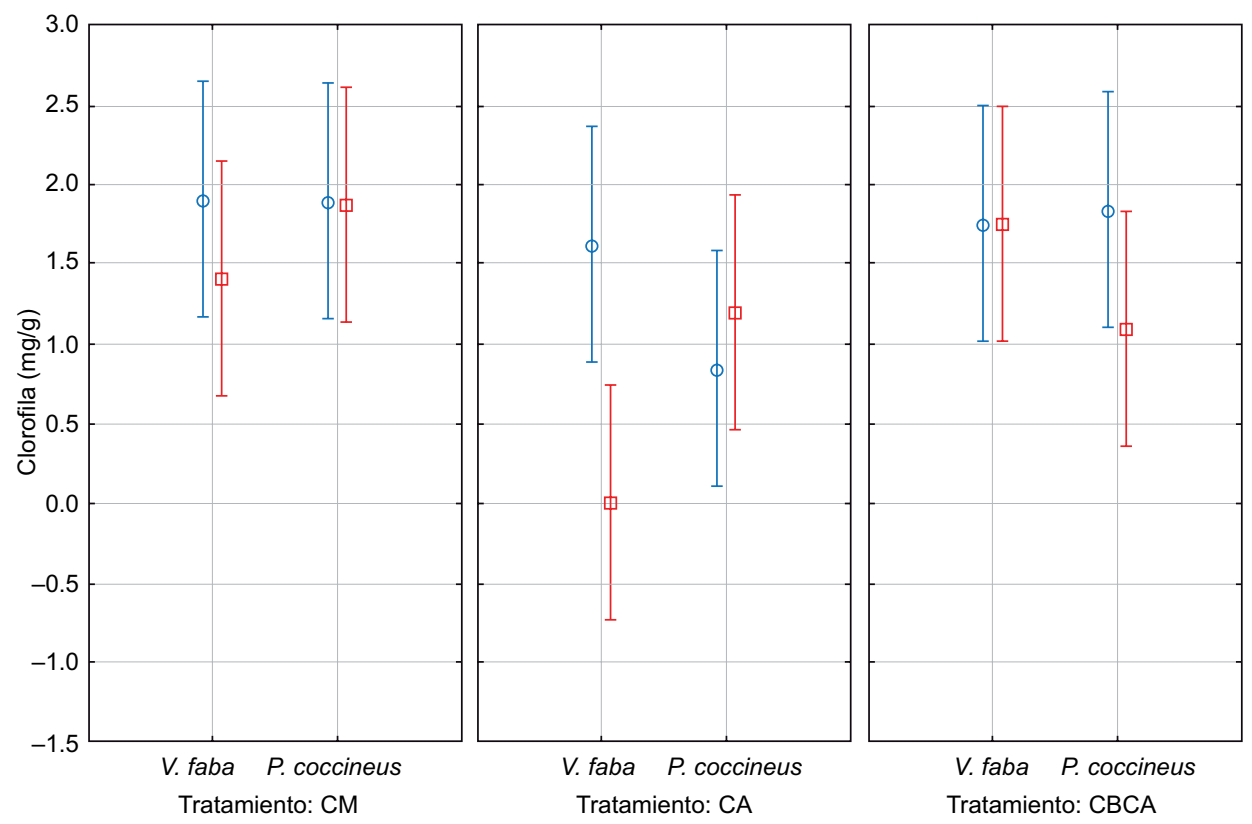

Ф 28 días $\overline{\text { 中 }} 60$ días

Fig. 6. Concentración de clorofila en $V$. faba y $P$. coccineus a los 28 y 60 días de experimentación en tres diferentes tratamientos, donde $\mathrm{CM}=$ composta madura, $\mathrm{CA}=$ composta con aceite, $\mathrm{CBCA}=$ composta con aceite bioaumentada

CUADRO V. PRUEBA DE TUKEY PARA LA VARIABLE CONCENTRACIÓN DE CLOROFILA ENTRE Vicia faba Y Phaseolus coccineus

\begin{tabular}{llllc}
\hline & & \multicolumn{2}{c}{ Tratamiento } \\
\cline { 4 - 5 } Corte & Especie & Tratamiento & $\begin{array}{c}\text { CA } \\
\text { V.faba (60 días) }\end{array}$ & $\begin{array}{c}\text { CM } \\
\text { P. coccineus (60 días) }\end{array}$ \\
\cline { 4 - 5 } & & & \multicolumn{2}{c}{$\mathrm{p} \leq 0.05$} \\
\hline 28 días & V. faba & CM & $0.035^{*}$ & 1 \\
28 días & P. coccineus & CM & $0.036^{*}$ & 1 \\
28 días & P. coccineus & CBCA & $0.046^{*}$ & 0.999 \\
60 días & V.faba & CA & 1 & $0.039^{*}$ \\
\hline
\end{tabular}

$*$ = muestran los tratamientos que tuvieron mayores diferencias significativas $(\mathrm{p} \leq 0.05)$, donde $\mathrm{CM}=$ composta madura, $\mathrm{CA}=$ composta con aceite, $\mathrm{CBCA}=$ composta con aceite bioaumentada

Los constituyentes tóxicos de hidrocarburos tales como los compuestos de bajo punto de ebullición, compuestos insaturados, compuestos aromáticos (benceno, naftaleno, fenantreno) y ácidos, provocan en las plantas una menor producción de clorofila. Estos compuestos al penetrar en las raíces, pueden viajar entre los espacios intracelulares y posteriormente por el sistema vascular, dañando las membranas celulares y con ellas la pérdida del contenido celular, con lo que se reduce la transpiración, se bloquea la apertura de estomas y se reduce la fotosíntesis (Baker 1970).
Akujobi et al. (2011), realizaron un estudio para evaluar los efectos que tienen los hidrocarburos en la disminución de pigmentos y contenido de proteína de Solanum melongena, reportando que los menores contenidos de proteína y clorofila se obtuvieron a concentraciones de aceite diésel de $10 \%$ en comparación con el tratamiento testigo sin diésel. También determinaron que las concentraciones de clorofila y proteínas pueden remediarse con la adición de nutrientes orgánicos, especialmente desechos de aves de corral, dando efectos significativos en el proceso de remediación de contaminantes provenientes del petróleo. 
CUADRO VI. ANÁLISIS DE CORRELACIÓN DE PEARSON PARA LAS VARIABLES AGRONÓMICAS ENTRE Vicia faba Y Phaseolus coccineus

\begin{tabular}{lccccc}
\hline & $\begin{array}{c}\text { Altura } \\
(\mathrm{cm})\end{array}$ & $\begin{array}{c}\text { Diámetro del } \\
\text { tallo }(\mathrm{cm})\end{array}$ & $\begin{array}{c}\text { Longitud } \\
\text { radicular }(\mathrm{cm})\end{array}$ & $\begin{array}{c}\text { Volumen } \\
\text { radicular }\left(\mathrm{cm}^{3}\right)\end{array}$ & $\begin{array}{c}\text { Clorofila } \\
(\mathrm{mg} / \mathrm{g})\end{array}$ \\
\hline Altura $(\mathrm{cm})$ & 1.000 & 0.506 & $0.746^{*}$ & 0.499 & 0.616 \\
Diámetro del tallo $(\mathrm{cm})$ & & 1.000 & 0.648 & 0.525 & 0.599 \\
Longitud radicular $(\mathrm{cm})$ & & & 1.000 & $0.851^{*}$ & 0.482 \\
Volumen radicular $\left(\mathrm{cm}^{3}\right)$ & & & & 1.000 & 0.399 \\
Clorofila $(\mathrm{mg} / \mathrm{g})$ & & & & 1.000 \\
\hline
\end{tabular}

$*=$ muestran la correlación entre las variables $(\mathrm{p} \leq 0.05)$

Con los coeficientes de correlación de Pearson, se determinó que las variables con mayor correlación fueron la altura y la longitud radicular, así como el volumen radicular y la longitud radicular (Cuadro VI).

Por lo tanto, esta relación de variables es determinante para el monitoreo de la fitotoxicidad de aceite quemado de las dos especies de plantas, siendo los principales indicadores del desarrollo de una especie vegetal. Sin embargo, a concentraciones elevadas de hidrocarburos $P$. coccineus interrumpe la síntesis de clorofila en las hojas, reduciendo la fotosíntesis y por lo tanto el contenido de clorofila de la planta, induciendo la inhibición del crecimiento, tanto en la zona radicular, como en la parte aérea (Wang et al. 2011).

\section{CONCLUSIONES}

Las semillas de $P$. coccineus presentaron mayor \% GRS, es decir, tuvieron mayor tolerancia a las concentraciones de hidrocarburos debido a las características físicas de la semilla. Las plantas testigo (CM) se desarrollaron de manera óptima en ambas especies estudiadas. Para el tratamiento de CA sólo se presentó supervivencia en las plantas de $P$. coccineus, en el tratamiento CBCA el mayor crecimiento fue para las plantas de $P$. coccineus. La variable agronómica que tuvo mayor influencia en el crecimiento de las dos especies vegetales fue la longitud radicular, siendo este sistema el que presenta una influencia directa para el transporte de nutrientes, y es aquí en donde se encuentran las mayores asociaciones e interacciones microbianas, las cuales determinan la transformación de compuestos de aceite automotriz. Por lo anterior, se observó que la especie con mayor tolerancia a las concentraciones de aceite automotriz fue $P$. coccineus, resistiendo desde la etapa germinativa y durante toda la etapa experimental, y para $V$. faba existió una alta toxicidad ante la presencia de aceite automotriz, inhibiendo el crecimiento y la germinación.
Las respuestas obtenidas en el presente estudio reflejan a $V$. faba y a $P$. coccineus como buenos indicadores de la toxicidad de aceite automotriz usado, teniendo con esto una valiosa herramienta para el monitoreo ambiental de suelos contaminados por hidrocarburos.

Asimismo, V.faba fue la especie más sensible para el monitoreo de la toxicidad del aceite automotriz, ya que los suelos utilizados aun presentaban concentraciones que llegan a mitigar el crecimiento de esta especie. Por lo que se recomienda ampliar el tiempo de tratamiento durante la técnica de biodegradación microbiana y repetir el ensayo de fitotoxicidad, para poder determinar el tiempo óptimo de biorremedición de aceite automotriz usado.

\section{REFERENCIAS}

Acuña M. L. (2011). Evaluación agronómica de la fecha de siembra en habas determinadas (Vicia faba L. var. Major) en Valdivia, Región de Los Ríos. Tesis de Licenciatura. Universidad Austral de Chile, Valdivia, Chile, 53 pp.

Adam G. y Duncan H. (2002). Influence of diesel fuel on seed germination. Environ Pollut. 120 (2), 363-370. DOI: 10.1016/S0269-7491(02)00119-7

Adenipekun C. O. y Oyetunji O. J. (2008). Effect of spent engine oil on the growth parameters and chlorophyll content of Corchorus olitorius Linn. Environmentalist 28 (4), 446-450.

DOI: $10.1007 / \mathrm{s} 10669-008-9165-5$

Adenipekun C., Oyetunji O. y Kassim L. (2009). Screening of Abelmoschus esculentus L. Moench for tolerance to spent engine oil. J. Appl. Biosci. 20, 1131-1137.

Agurto E. S. (2012). Análisis de compuestos antioxidantes presentes en haba (Vicia faba L.) para su consumo hortícola. Tesis de Licenciatura. Facultad de Ciencias Agronómicas, Universidad de Chile, Santiago, Chile, $47 \mathrm{pp}$. 
Akujobi C., Onyeagba R., Nwaugo V. y Odu N. (2011). Protein and chlorophyll contents of Solanum melongena on diesel oil polluted soil amended with nutrient supplements. Curr. Res. J. Biol. Sci. 3 (5), 516-520.

Arnol D. I. (1949). Copper enzymes in isolated chloroplasts polyphenoloxidase in Beta vulgaris. Plant Physiol. 24 (1), 1-16.

Ates E. (2011). Influence of some hardseedednessbreaking treatments on germination in Persian clover (Trifolium resupinatum ssp. Typicum fiori et paol.) seeds. Rom Agric Res. 28, 229-236.

Azcón-Bieto J. y Talón M. (2008). Fundamentos de fisiología vegetal. 2 ed. McGraw-Hill Interamericana. Barcelona, España, 656 pp.

Baker J. M. (1970). The effects of oils on plants. Environ. Pollut. 1 (1), 27-44.

DOI: 10.1016/0013-9327(70)90004-2

Benavides L. D., Quintero M. G., Guevara V.A., Jaimes C. D., Gutiérrez R. S. y Miranda G. J. (2006). Biorremediación de suelos contaminados con hidrocarburos derivados del petróleo. NOVA- Publicación Científica 4 (5), 82-90.

Bergareche C., Vidal D. y Simón E. (1988). Componentes de la producción en un cultivo de Vicia faba sometido a fertilización nitrogenada. ARXIUS de 1 Esc. Sup. d Agricultura de Barcelona 4 (11), 43-58.

Castillo G. (2004). Ensayos toxicológicos y métodos de evaluación de calidad de aguas. Estandarización, intercalibración, resultados y aplicaciones. 1a ed. Centro Internacional de Investigaciones para el Desarrollo, Distrito federal, México, 202 pp.

Chávez-Santibáñez P. I. y Castro-González T. A. (2013). Caracterización del proceso de composteo para la biodegradación de aceite lubricante usado, para motores de combustión interna de diésel. Tesis de Licenciatura. Universidad Autónoma Metropolitana, Unidad Azcapotzalco, Distrito federal, México, 41 pp.

Confalone A., Boote K., Lizaso J. y Sau F. (2010). Predicción de la fenología de Vicia faba L.: estimación de parámetros con el modelo CROPGRO- faba bean usando experimentos de múltiples fechas de siembra. Memorias. XIII Reunión Argentina y VI Latinoamericana de Agrometeorología 2010 de la Asociación Argentina de Agrometeorología. Bahía Blanca Argentina. 18 al 22 de octubre, 2010. CD-ROM.

Córdoba-Rodríguez D., Vargas-Hernández J. J., LópezUpton J. y Muñoz-Orozco A. (2011). Crecimiento de la raíz en plantas jóvenes de Pinus pinceana Gordon en respuesta a la humedad del suelo. Agrociencia 45 (4), 493-506.

Escalante E. E. (2000). Estudio de ecotoxicidad de un suelo contaminado con hidrocarburos. Tesis de Maestría. Universidad Autónoma Metropolitana, Unidad Iztapalapa, Distrito federal, México, 86 pp.
Ferrera-Cerrato R., Alarcón A., Mendoza-López M. R., Sangabriel W., Trejo-Aguilar D., Cruz-Sánchez J. S. y Delgadillo-Martínez J. (2007). Fitorremediación de un suelo contaminado con combustóleo utilizando Phaseolus coccineus y fertilización orgánica e inorgánica. Agrociencia 41 (8), 817-826.

García G. E., García N. E., Juárez S. L., Juárez S. L., Montiel G. J. y Gómez C. M. (2012). La respuesta de haba (Vicia faba, L.) cultivada en un suelo contaminado con diferentes concentraciones de cadmio. Rev. Int. Contam. Ambie. 28 (2), 119-126.

García-Albarado J. C., Trejo-Téllez L. I., VelásquezHernández M. A., Ruiz-Bello A. y Gómez-Merino F. C. (2010). Crecimiento de petunia en respuesta a diferentes proporciones de composta en sustrato. Rev. Chapingo Ser. Hortic. 16 (2), 107-113.

García L. R. (2010). Biodisponibilidad de aceite automotriz usado mediante Aspergillus niger impulsado por nanojets. Tesis de Licenciatura. Universidad Autónoma Metropolitana, Unidad Azcapotzalco, Distrito federal, México, 78 pp.

Garrido-Hoyos S. E., del Campo-Sánchez M. G., VacaPaulín R. y Lugo-de la Fuente J. A. (2005). Aprovechamiento de biosólidos y composta en el cultivo de haba (Vicia faba L.). Ingeniería hidráulica en México 20 (4), 121-135.

Gogosz A., Bona C., Santos G. y Botosso P. (2010). Germination and initial growth of Campomanesia xanthocarpa O. Berg. (Myrtaceae), in petroleumcontaminated soil and bioremediated soil. Braz. J. Biol. 70 (4), 977-986.

DOI: $10.1590 / \mathrm{S} 1519-69842010000500009$

Gonzáles J., Pastenes C. y Horton P. (2001). Efecto de la temperatura, el estrés hídrico y luminoso sobre la heterogenidad del fotosistema II en cuatro variedades de poroto (Phaseolus vulgaris L.). Rev. Chil. His. Nat. 74 (4), 779-791.

DOI: $10.4067 / \mathrm{S} 0716-078 X 2001000400006$

Gutiérrez-Miceli F. A., Oliva-Llaven M. A., RincónRosales R. y Dendooven L. (2006). Selección de genotipos de caña de azúcar usando características de cultivo de callos. Agrociencia 40 (5), 605-611.

Hoekstra N., Bosker T. y Lantinga E. (2002). Effects of cattle dung from farms with different feeding strategies on germination and initial root growth of cress (Lepidium sativum L.). Agric. Ecosyst. Environ. 93 (1-3), 189-196. DOI: 10.1016/S0167-8809(01)00348-6

Jong-Su S., Young-Soo K. y Qing X. L. (2009). Bacterial degradation of aromatic compounds. Int. J. Environ. Res. Public. Health. 6 (1), 278-309. DOI: 10.3390/ ijerph6010278

Khan D. y Shaukat S. S. (2009). Effects of diesel oilpolluted soil on emergence and growth of seedlings 
of Thespesia populnea (L.) sol. ex. corr. Int. J. Biol. Biotech. 6 (4), 289-298.

List M. H. (2014). Caracterización agronómica, nutrimental y molecular de Vicia faba L. Tesis de Maestría. Colegio de Posgraduados de Chapingo, Texcoco, Estado de México, México, 127 pp.

Lladó F. S. (2012). Biorremediación de suelos contaminados por hidrocarburos pesados y caracterización de comunidades microbianas implicadas. Tesis de doctorado, Facultad de Biología, Universidad de Barcelona. Barcelona, España, 272 pp.

Manzur J. P. (2013). Técnicas y estrategias de mejora para facilitar la hibridación interespecífica y el acortamiento del ciclo generacional en el género Capsicum. Tesis de Doctorado. Universidad Politécnica de Valencia, Valencia, España, 174 pp.

Meckenstock R. U. y Mouttaki H. (2011). Anaerobic degradation of non-substituted aromatic hydrocarbons. Curr. Opin. Chem. Biol. 22 (3), 406-414.

DOI: 10.1016/j.copbio.2011.02.009

Mecozzi M. y Sturchio E. (2015). Effects of essential oil treatments on the secondary protein structure of Vicia faba: A mid-infrared spectroscopic study supported by two-dimensional correlation analysis. Spectrochim. Acta Mol. Biomol. Spectrosc. 137, 90-98. DOI: 10.1016/j.saa.2014.08.020

Merkl N., Schultze-Kraft R. e Infante C. (2005). Assessment of tropical grasses and legumes for phytoremediation of petroleum-contaminated soils. Water Air Soil Poll. 165 (1), 195-209.

DOI: $10.1007 / \mathrm{s} 11270-005-4979-y$

Meza L. N. (2014). Biodiversidad de frijol (Phaseolus culgaris L.) en Honduras, caracterización agromorfológica, molecular y ecogeográfica. Tesis de Doctorado. Escuela Técnica Superior de Ingenieros Agrónomos, Universidad Politécnica de Madrid, Madrid España, 171 pp.

Mills T., Arnold B., Sivakumaran S., Northcott G., Vogeler L., Robinson B. y Leonil D. (2006). Phytoremediation and long-term site management of soil contaminated with pentachlorophenol (PCP) and heavy metals. J. Environ. Manage. 79 (3), 232-241.

DOI: 10.1016/j.jenvman.2005.07.005

Miranda D. y Restrepo R. (2005). Los derrames de petróleo en ecosistemas tropicales-impactos, consecuencias y prevención. La experiencia en Colombia. Memorias. International oil spill proceedings 2005 (1), 571-575. DOI: $10.7901 / 2169-3358-2005-1-571$

Ndubuisi A., Ugbede A., Ekpo I. A., Nkachukwu P. y Bessong R. (2013). Effect of crude oil pollution on growth parameters, chlorophyll content and bulbils yield in air potato (Dioscorea bulbifera L.). Int. J. Appl. Sci. Tech. 3 (4), 37-42.
Nwoko C. O., Okeke P. N., Agwu O. O. y Akpan I. E. (2007). Performance of Phaseolus vulgaris L. in a soil contaminated with spent-engine oil. Afr. J. Biotechnol. 6 (16), 1922-1925.

Oyedeji A. A., Adebiyi A. O., Omotoyinbo M. A. y Ogunkunle C. O. (2012). Effect of crude oil-contaminated soil on germination and growth performance of Abelmoschus esculentus L. Moench-A widely cultivated vegetable crop in Nigeria. Am. J. Plant. Sci. 3, 1451-1454. DOI: 10.4236/ajps.2012.310174

Pernía B., De Sousa A., Reyes R. y Castrillo M. (2008). Biomarcadores de contaminación por cadmio en las plantas. Interciencia 33 (2), 112-119.

Pinales J. F. (1995). Estudio agrobiológico de frijol Ohaseolus vulgaris bajo condiciones de riego y punto de riego en Anáhuac, Nuevo León. Tesis de Maestría. Facultad de Ciencias Biológicas, Universidad Autónoma de Nuevo León, Monterrey, Nuevo León, México, 113 pp.

Pino N. J., Carvajal S., Gallo A. y Peñuela G. (2012). Comparación entre bioestimulación y bioaumentación para la recuperación de suelos contaminados con diésel. Producción más Limpia 7 (1), 101-108.

Prieto F. G., Callejas J. H., Román A. D., Prieto J. M., Gordillo A. J. y Marzo M. M. (2007). Acumulación de arsénico en el cultivo de habas (Vicia faba). Agronomía Costarricense 31 (2), 101-109.

Prince R. (1993). Petroleum spill biorremediation in marine environments. Microbiol. 19 (4), 217-242. DOI: $10.3109 / 10408419309113530$

Ramírez M., Suárez H., Regino M., Caraballo B. y García E. D. (2012). Respuesta a tratamientos pregerminativos y caracterización morfológica de plántulas de Leucaena leucocephala, Pithecellobium dulce y Ziziphus mauritiana. Pastos y Forrajes 35 (1), 29-42.

Rao N. K., Hanson J., Dulloo M. E., Ghosh K., Nowell D. y Larinde M. (2006). Manual of seed handling in genebanks. En: Handbooks for genebanks. Bioversity International. Rome, Italy, $65 \mathrm{pp}$.

Reynoso-Cuevas L., Gallegos-Martínez M., Cruz-Sosa F. y Gutiérrez-Rojas M. (2008). In vitro evaluation of germination and growth of five plant species on medium supplemented with hydrocarbons associated with contaminated soils. Bioresour. Technol. 99 (14), 6379-6385. DOI: 10.1016/j.biortech.2007.11.074

Rivera-Cruz M. D., Maldonado-Chávez E. y TrujilloNarcía A. (2012). Effects of crude oil on the growth of Brachiaria mutica and Leucaena leucocephala and on soil and plant macronutrients. Trop. Subtrop. Agroecosyst. 15 (2), 530-539.

Sangabriel W., Ferrera-Cerrato R., Trejo-Aguilar D., Mendoza-López M. R., Cruz-Sánchez S. y López-Ortiz C. (2006). Tolerancia y capacidad de fitorremediación 
de combustóleo en el suelo por seis especies vegetales. Rev. Int. Contam. Ambie. 22 (2), 63-73.

SEMARNAT (2002). Norma Oficial Mexicana. NOM021-SEMARNAT-2000. Especificaciones de fertilidad, salinidad y clasificación de suelos Estudios, muestreos y análisis. 85. México: Diario Oficial de la Federación. 31 de diciembre de 2002.

SEMARNAT (2003). Norma Oficial Mexicana NOM-138SEMARNAT/SS-2003. Límites máximos permisibles de hidrocarburos en suelos y las especificaciones para su caracterización y remediación. Secretaría de Medio Ambiente, Recursos Naturales y Pesca. Diario Oficial de la Federación. 29 de marzo de 2005.

Shanee S., Tanveer A., Javaid M. M., Chaudhry K. M., Aziz A. y Khaliq A. (2011). Phytotoxic effects of Euphorbia dracunculoides: a weed of rainfed chickpeachickpea cropping system. S. J. Agri. Res. 9 (2), 580588. DOI: 10.5424/sjar/20110902-061-10

Shirdam R., Zand A. D., Bidhendi G. N. y Mehrdadi N. (2008). Phytoremediation of hydrocarbon-contaminated soils with emphasis on the effect of petroleum hydrocarbons on the growth of plant species. Phytoprotection 89 (1), 21-29. DOI: 10.7202/000379ar

Terefe H., Fininsa C., Sahile S. y Tesfaye K. (2015). Effect of temperature on growth and sporulation of Botrytis fabae, and resistance reactions of faba bean against the pathogen. J Plant. Pathol. Microb. 6 (7), 285.

DOI: $10.4172 / 2157-7471.1000285$
VanOverbeek J. y Blondeau R. (1954). Mode of action of phytotoxic oils. Weed 3 (1), 55-65.

DOI: $10.2307 / 4040131$

Villarreal-Romero M., Hernández-Verdugo S., SánchezPeña P., García-Estrada R. S., Osuna-Enciso T., ParraTerrazas S. y Armenta-Bojorquez A. D. (2006). Efecto de cobertura del suelo con leguminosas en rendimiento y calidad del tomate. Terra. Latinoam. 24 (4), 549-556.

Wang J., Liu X., Zhang X., Liang X. y Zhang W. (2011). Growth response and phytoremediation ability of Reed for diesel contaminant. Procedia. Environ. Sci. 8, 6874. DOI: 10.1016/j.proenv.2011.10.013

Wu C., Chen X. y Tang J. (2005). Lead accumulation in weed communities with various species. Commun. Soil Sci. Plant. Anal. 36 (13-14), 1891-1902. DOI: $10.1081 / C S S-200062486$

Yu M., Shi-Ying B., Jin-Guo H., Jian-Ping G., Yu-Hua H., Xue-Jun W. y Zong X. (2013). Genetic linkage map of Chinese native variety faba bean (Vicia faba L.) based on simple sequence repeat markers. Plant. Breeding. 132 (4), 397-400. DOI: 10.1111/pbr.12074

Zarinkamar F., Reypour F. y Soleimanpour S. (2013). Effect of diesel fuel contaminated soil on the germination and the growth of Festuca arundinacea. Res. J. Chem. Environ. 1, 37-41. 